\title{
Correction to: e-TEP repair for midline primary and incisional hernia: technical considerations and initial experience
}

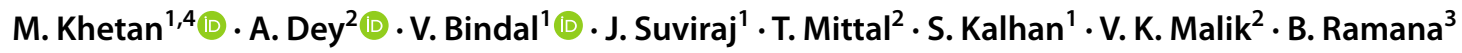

Published online: 19 April 2021

○ Springer-Verlag France SAS, part of Springer Nature 2021

Correction to: Hernia

https://doi.org/10.1007/s10029-021-02397-6

The surname and given name of co-author has been interchanged. The correct name has been copied below:

B. Ramana

The original article has been corrected.

Publisher's Note Springer Nature remains neutral with regard to jurisdictional claims in published maps and institutional affiliations.

The original article can be found online at https://doi.org/10.1007/ s10029-021-02397-6.

M. Khetan

khetan.mukund@gmail.com
A. Dey
ashishdey2006@gmail.com
V. Bindal
bindal.vivek@gmail.com
J. Suviraj
drsuvirajjohn@gmail.com
T. Mittal
tarunmittalmas@gmail.com
S. Kalhan
sudhirkalhan@gmail.com
V. K. Malik
vinod.k.malik@gmail.com

B. Ramana

rambodoc@gmail.com

1 Department of Minimal Access and Bariatric Surgery, Sir Ganga Ram Hospital, Old Rajinder Nagar, New Delhi 110060, India

2 Department of General and Laparoscopic Surgery, Sir Ganga Ram Hospital, Old Rajinder Nagar, New Delhi 110060, India

3 Calcutta Medical Research Institute, Kolkata, India

4 Institute of Minimal Access, Metabolic and Bariatric Surgery, Sir Ganga Ram Hospital, Room no 400, SWB block, 4th floor Rajinder Nagar, New Delhi 110060, India 